\title{
Type of Parental Socialization across Cultures A Psychoanalysis Review
}

\author{
Samah Khaled Abd El Kawy Zahran \\ Child Education Department, Women's College, Ain Shams University, Cairo, Egypt. \\ Email: skhaekz@yahoo.com \\ Received April 23 ${ }^{\text {rd }}$, 2011; revised June 5 $5^{\text {th }}, 2011$; accepted July $12^{\text {th }}, 2011$.
}

\begin{abstract}
In order to study parental socialization (Styles) cross-culturally, it is necessary to understand the different styles of parenting in culture throughout the world, also the effects of culture's variables on parenting styles. The research discusses this notion through: definitions, specific theories and psychoanalysis for the theoretical framework. Then the study suggests a new type of socialization (parenting styles) as a result of the new global culture.
\end{abstract}

Keywords: Culture, Parenting Socialization (Styles), Intermediate Variables, Mixed Culture, Acculturation

\section{Introduction}

During the first years of life parents assume special importance. As parents guide their young children from complete infantile dependence into the beginning stages of autonomy. This process can be called parental socialization and socialization refers to the process of inheriting norms, customs and ideologies. It may provide the individual with the skills and habits necessary for participating within their own society; a society develops a culture through a plurality of shared norms, customs, values, traditions, social roles, symbols and languages. Socialization is thus: the means by which social and cultural continuity are attained (John, 1968). So, parents styles of care giving can have both immediate and lasting effects on children's social functioning in areas from moral development to peer play to academic achievement (Bornstein, 2007). Interpersonal relationships have unparalleled developmental implications for humans everywhere, regardless of age, gender, race, ethnicity, culture, socioeconomic status, and geographic boundaries (Duck, 1999). For children, parent-child relationships are particularly important. A vast research literature shows that the quality of parent-child relationships characterized by parental acceptance (love) and rejection (lack of love) is a major predictor of psychological functioning and development for both children and adults universally (Khaleque \& Rohner, in press; Rohner, 1975, 2002; Rohner \& Rohner, 1980). A significant portion of this research dealing with the quality of parent-child interactions relates to parental acceptance-rejection theory. While, parenting- child interpersonal relationship is important, the topic of culture and parenting holds interest on many different levels, also. Parenting represents both a universal, if not taken for granted, feature of everyday family life and individual autobiographical experience, even as it also varies markedly across different cultural, social, and historical contexts. Implicated in processes of psychological development and intergenerational influence, parenting is fundamental to human survival as well as to processes of cultural transmission and change (Miller, 2001).

\section{Culture}

Human infants are born without any culture. The general process of acquiring culture is referred to as socialization. While socialization refers to the general process of acquiring culture, anthropologists use the term enculturation for the process of being socialized to a particular culture. You were acculturated to your specific culture by your parents and the other people who raised you. Socialization is a learning process that begins shortly after birth. Early childhood is the period of the most intense and the most crucial socialization. It is then that we acquire language and learn the fundamentals of our culture (O’Neil, 2008).

Culture is the system of information that codes the manner in which the people in an organized group, society or nation interact with their social and physically environment. In this sense, the term refers to a frame of reference for the group or collection of persons who shared that patterned system (Reber, 1995). So that; culture is socially learned and socially transmitted, it travels from an individual or group to another, so it cannot be studied as static entity; culture exists into motion (Morgan et al., 2005). Yet, culture is reflected in any group that shares a history and belief system that influences how they function. It is important to distinguish societal culture and home culture. Societal culture is made up of the institutions in a society that express the group's value system (educational systems, medical systems, political systems, religious systems, the media, etc.). Home culture is made of the values of the immediate family. Sometimes, home culture can conflict with the societal culture (Ontai et al., 2010). The psychosocial development of children depends, of course, to a great extent on how they are raised by their parents. Children's behavior and development influence parents' behavior, too, interacting with it. Culture affects these parenting styles and practices and child-parent relationships, because parents usually rise and deal with their children according to the values and norms endorsed in their own culture (Dwairy et al., 2006). Culture constitutes a strong factor in structuring parental practices because it can transmit guidelines about parenting (Dwairy et al., 2006). 
There are cultural and ethnic variations that produce value systems which essentially direct parent's manner and styles of parenting. This paper attempts to discuss three types of cultures: A) Collective or independent pattern as it appears, for example in Asian, Native Hispanic, African and Asian American and non western countries. Whom families take time to inculcate to their children: the values and beliefs that their ancestors had ingrained to the former generations. The way families are joint together as a social unit uniquely cultural in nature (Wong, 2002). For example, Native and Hispanic American families focus on family and kinship helping patterns, while African American families tend to promote family and kinship helping but also believe strongly in the importance of individual achievement. Generally, this pattern of culture believes that social skills should be nurtured as much as academic skills. Also, immigrant parents from Latin America may view how their child is behaving in classroom just as important as what there is learning (Tcet, 2010). B) Individual or independence as it appears in European American and western counties; European American in contrast; they promote more individualistic and independent thinking and nurturing styles that are vastly different from their Asian American counterparts. According to studies, European American emphasized self-esteem, stressing the personal well being in individual (Wong, 2002). Parents from cultures embracing individualism expect competition and an emphasis on individual accomplishments in school (Tcet, 2010). Cultural values can commonly be divided into "independence" or "interdependence". The US culture commonly stresses values of "independence" while non-Western cultures focus more on interdependence. The most important goal of raising independent children is for them to be self-sufficient and act on their own personal choices. On the other hand, the primary goal of raising interdependent children is for them to be part of a larger system of relationships - to "depend" on others for well-being. A range of both independence and interdependence can be seen in any family or culture (Ontai et al, 2010). C) Mixed cultures - which are the new variable in the current study and means that the cultures were collective then exposed to western cultures then absorbed their cultures and become mixed of both, like some Arabic countries and some immigrants in Australia and United States of America, for example. So that their types of rearing become mixed of individual (independence) and collective (interdependence) type of culture.

Culture is dynamic in nature and changes across generations and geographical locations. Overarching societal and economic conditions have tremendous influences on cultural practices. However, there are ways of organizing thinking about culture that can be helpful as a beginning point for understanding parenting (Tcet, 2010).

\section{Parental Socialization}

On the other hand, a parenting style is a psychological construct representing standard strategies that parents use in their child rearing. There are many differing theories and opinions on the best ways to rear children, as well as differing levels of time and effort that parents are willing to invest. Many parents create their own style from a combination of factors, and these may evolve over time as the children develop their own personalities and move through life's stages. Parenting style is affected by both the parents' and children's temperaments, and is largely based on the influence of one's own parents and culture. Most parents learn parenting practices from their own parents-some they accept, some they discard. The degree to which a child's education is part of parenting is a further matter of debate (Maccoby, 1983; Chan et al., 2008). Maccoby and Martin (1983) identified two particular dimensions of parenting behaviors: whether they were strict (controlling) or permissive (gave a great deal of autonomy), and whether they were accepting and responsive or rejecting and unresponsive. Based upon these two dimensions four parenting styles were identified. Baumrind (1971) identified three parenting styles: authoritarian, authoritative, and permissive. The latter was later divided into two forms, permissive neglectful and permissive indulgent (Tcet, 2010). Parenting style can also be defined as a pattern of attitude that parenting exhibit toward the upbringing of their children (Zervides et al., 2007).

This definition of parenting style is consistent with the earliest research on socialization. While, socialization is a process that: enables individual to integrate into and behave adaptively within a society. It is a lifelong experience. However, the dominant usage of the term is with respect to the processes by which the child becomes inculcated with society's values and with his or her own social roles (Reber, 1995). Interest in the influence of parents' behavior on child development was a natural outgrowth of both behaviorist and Freudian theory. Child behaviorists were interested in how the parenting of reinforcement in the near environment shaped development. Freudian theorists, in contrast, argued that the basic determinants of development were biological and inevitably in conflict with parental desires and societal requirements. This interaction between the child's libidinal needs and the family environment was presumed to determine individual difference in children's development. The psychodynamic model concentrated their efforts on emotional relationship between the parent and child and its influence on the child's psychosexual, psychosocial, and personality development. The learning model focuses on parental practices rather than attitudes. Because differences in children's development were through to reflect differences in the learning environment to which they had been exposed, measures of parenting style were designed to capture the parenting of behaviors that defined theses environment (Darling \& Sternberg, 1993).

Parental acceptance-rejection theory (PARTheory) is a theory of socialization that attempts to predict and explain worldwide causes, consequences, and other correlates of parental acceptance-rejection. Additionally, the theory attempts to predict and explain the consequences of acceptance-rejection in other primary interpersonal relationships, including intimate adult relationships. This theory is aimed to predict and explain major causes, consequences, and correlates of parental acceptance and rejection within the United States and worldwide (Rohner, 1980, 1986, 2001). PAR Theory attempts to answer five classes of questions concerning parental acceptance and rejection. These questions are divided into the theory's three subtheories: personality subtheory, coping subtheory, and sociocultural systems subtheory. In particular, personality postulates that rejected children are likely to feel anxious and insecure. Additionally, parental rejection is expected to lead to other personality outcomes in children and adults including: hostility, aggression, passive aggression, or problems with the 
management of hostility and aggression; dependence or defensive independence, depending on the form, frequency, and intensity of rejection; impaired self-esteem; impaired self-adequacy; emotional unresponsiveness; emotional instability; and negative worldview. About coping subtheory, Studies in the United States and across the world confirm PAR Theory's assumption that nearly 80 percent of children and adults-irrespective of geographic location, race, and ethnicity-generally tend to be negatively affected by parental rejection (Rohner, 2001, 2002). PAR Theory's sociocultural systems subtheory attempts to predict and explain major causes and sociocultural correlates of parental acceptance and rejection worldwide. The subtheory predicts, for example that children are likely to develop cultural beliefs about the supernatural world (God and spiritual beings) as being malevolent (i.e. hostile, treacherous, destructive, or negative in some way) in societies where they tend to be rejected. On the other hand, the supernatural world is expected to be perceived as benevolent (i.e. warm, generous, protective, or positive in some other way) in societies where most children are raised with love and acceptance. Substantial cross-cultural evidence confirms these predictions (Rohner, 1975, 1986). So PAR Theory from 1960 till 2002, all over the world can be applied on thousands of people and dozen nations, language group internationally, which gives evidence lends credibility to PAR Theory's contention that the experience of parental rejection is one irreducible, root-cause of social, emotional, behavioral, and social-cognitive problems in the development of children, adolescents, and adults everywhere-regardless of differences in gender, ethnicity, race, language, sociocultural background, or other such defining conditions. Because perceived acceptance-rejection appears to have a consistent effect on all humans the possibility is opened for creating culture-fair policies and programs, interventions, treatment, and other practical applications for enhancing human welfare everywhere (Rohner, 2002).

Also, Baumrind Theory (1966, 1967, and 1991) —as mentioned before has identified three basic styles of child rearing: authoritarian, permissive, and authoritative. The three parenting styles differ in two particular areas of parenting: the amount of nurturing (or warmth) a child receives and the extent to which a child's activities and behavior are controlled (Baumrind, 1991). Parents who practice the authoritarian style emphasize their control of the child and his or her obedience. They restricts the autonomy of the child and decrees what behavior is appropriate for him or her (Baumrind, 1966; Reitman, Rhode, Hupp, \& Altobello, 2002). These parents favor enforced discipline, usually demanding unquestioned adherence to their wishes, and expect children to follow their orders immediately. They are the sole regulating authority in the child's life, using punishment to control him or her, and seldom explain the reasoning behind rules and regulations. The nurturing skills of authoritarian parents tend to be low. They rarely use words of comfort and are unlikely to demonstrate affection or to praise their adolescents.

Permissive parents encourage their children's autonomy and enable them to make their own decisions and regulate their own activities. They avoid confrontation and tend to be warm, supportive people and do not care to be viewed by a child as a figure of authority. The nurturing skills of parents who adopt the permissive style tend to be moderate to high, whereas their control of their children is poor (Baumrind, 1991; Reitman et al., 2002). The authoritarian and permissive parenting styles are considered to be the two poles of a continuum, whereas the authoritative style lies somewhere in the middle. Parents who adopt this style tend to have good nurturing skills and exercise moderate parental control to allow the child to become progressively more autonomous (Baumrind, 1966, 1967, 1991; Reitman et al., 2002). Children reared in this style are not completely restricted but rather are allowed a reasonable degree of latitude in their behavior. Authoritative parents do enforce limits in various ways such as reasoning, verbal give and take, overt power, and positive reinforcements. Most Western parents adopt the authoritative style of child rearing. The authoritative parenting style has been associated with positive outcomes in terms of the child's psychosocial development. Numerous studies have presented evidence for the salutary effect of this style in North Americans. (Steinberg, Dornbusch, \& Brown, 1992; Steinberg, Lamborn, Dornbusch, \& Darling, 1992; Steinberg, Mounts, Lamborn, \& Dornbusch, 1991). Authoritarian and Permissive type of parenting can be found in (B) pattern of culture. Children of authoritative parents have a high level of self-esteem and tend to be self-reliant, self-controlled, secure, popular, and inquisitive (Buri, Louiselle, Misukanis, \& Mueller, 1988; Wenar, 1994). They manifest fewer psychological and behavioral problems than youth having authoritarian or permissive parents (Dwairy et al., 2006).

Children with this type of parenting may have less social competence as the parent generally tells the child what to do instead of allowing the child to choose by him or herself. This may be found in type (A) culture. Nonetheless, researchers have found that in some cultures and ethnic groups, aspects of authoritarian style may be associated with more positive child outcomes than Baumrind predicts. Aspects of traditional Asian child-rearing practices are often continued by Asian American families. In some cases, these practices have been described as authoritarian. While, children of permissive parents are tend to be more impulsive, and as adolescents, may engage more in misconduct and drug use. Children never learn to control their own behavior and always expect to get their way. But in the better cases they are emotionally secure, independent and are willing to learn and accept defeat. They are able to live life without the help of someone else. Children whose parents are neglectful develop the sense that other aspects of the parents' lives are more important than they are. Children often display contradictory behavior, and are emotionally withdrawn from social situations. This disturbed attachment also impacts relationships later on in life. In adolescence, they may show patterns of truancy and delinquency. Finally, authoritative parenting encourages children to be independent.

They are not usually as controlling, allowing the child to explore more freely, thus having them make their own decisions based upon their own reasoning (Maccoby, 1983; Chan et al., 2008). While, type (C) mixed culture, exhibit all these type of parenting styles, according to situations, children's age and gender, parents' level of education, etc. Related studies in Arabic countries have shown that parenting styles become permissive with children than adolescence and with male than female, also it is permissive in some situations like nutrition, but authoritative in other situations, they consider more important like sexual one (Gaber, 1978). 


\section{Cultures and Family Systems}

It is common knowledge that cultures seem to have different types of family systems. In the United States and Canada and the countries of northern Europe the nuclear family, father, mother and the children, appears to predominate. In almost all of the rest of the world, extended families, the grandparents, father, mother, children, but also aunts, uncles, cousins, and other kin are considered to be "family." The 20th century has seen the greatest upheaval in history of family change. Family types in North America and northern Europe have been changing with the increase of nuclear families and the decrease of extended ones, and during the past 20 years or more, with the increase of unmarried or divorced families, unmarried mothers, and homosexual families. Nuclear families have also been increasing in all the continents of the world. The key to studying how family structure is related to function and how it effects psychological differentiation, and how family type is related to economic base and culture, is the nuclear family. Murdock made an important distinction (1949) regarding the relationship of the nuclear family to the extended family; that the extended family represents a constellation of nuclear families; the nuclear family of the paternal grandparents, the nuclear family of the maternal grandparents, the nuclear family of the married sons, married daughter, married cousins, etc. Thus, in focusing on a particular nuclear family, it is a mistake to assume it is an independent unit, but because the extended family is essentially a constellation of nuclear families across at least three-generations. The important question is the degree of contact and interdependence between this constellation of nuclear families. Parson's theory of the isolation of the nuclear family from its extended family and kinship network, leading to psychological isolation and anomie had a strong influence on psychological and sociological theorizing about the nuclear family. However, studies of social networks in North America and Northern Europe in the past 40 years have indicated that the nuclear family is not isolated from its kin not is it independent to the degree assumed by Parsons and other sociologists of the family. Nuclear families, even in industrial countries, have networks with grandparents, brothers, sisters and other kin. The question is the degree of contact and communication with these kin, even in nations of Northern America and northern Europe (Georgas, 2003).

\section{Some Variables that Affect Parental Socialization within the Same Culture}

Not only culture affects parenting styles, some reports indicated that there are some intermediate variables that influence the parenting styles also. Intermediate variables as: 1) First born children: Parents treat first-born children in a special way. Axelson (1999) claimed that first-born children tend to receive more attention, are likely to carry the family's ambitions, and are assigned a dominant role with respect to later children. This description fits the Arab first-born children, too, who carry the parents' aspirations, on one hand, and enjoy more parental attention, care, and indulgence, on the other. Some research indicates that a first-born Arab child is treated more gently than the other children in the family (Achoui, 2003; Al-Teer, 1997). These differences between first-born and other children are expected to influence the process of individuation and the parent-child connectedness. Also, First-born adolescents reported higher level permissive parenting than other adolescents (Dwairy, 2006). 2) Parent economical and educational level: Some reports indicated that parental education, economic level, and urbanization influence the parenting styles and practices. This association between socioeconomic classes and a harsh style of parenting is universal, and not specific to Arabs. More educated mothers were less authoritarian and controlling than less educated parents in Saudi Arabia (Al-Mutalq, 1981), Egypt (Hana, 1974), and Algeria (Sahrawi, 1998). Mahmoud (1997) reported that mothers of a higher socioeconomic level tend to be more authoritative and encouraging of their children's independence than lower socioeconomic-level mothers. In a comparison between gifted children and nongifted children, parenting of gifted Palestinian children was more authoritative and less authoritarian. It is interesting that authoritarian parenting was associated with poorer mental health of gifted but not of nongifted children (Dwairy, 2004b in Dwairy, 2006). Modernization, a theory developed by sociology and political science, hypothesizes that increasing economic level and industrialization in a society results in the rejection of traditional values and culture, and inevitable convergence toward a system of modern values and increasing individualization. One of the consequences of modernization is the transition of the extended family system in economically underdeveloped societies to the nuclear family characteristic of industrial societies (Georgas, 2003). 3) Goodness of fit between parents and children: Researchers have identified three styles of children: easy children: are calm, happy, adaptable, regular in sleeping and eating habits, positive in mood and interested in new experiences. Difficult children: are often fussy, irregular in feeding and sleeping habits, low in adaptability, fearful of new people and situations, easily upset, high strung, and intense in their reactions. Slow to warm up children: are relatively inactive, reflective, tend to withdraw or to react negatively to novelty, but their reactions gradually become more positive with experience. So that; the match or mismatch between a child's style and his/her parental way of socialization determines the harmony between them (www.aboutourkids.org, 2010).

4) Gender and generational changes in parenting: Researches indicated that males from two generations-big in forties and smaller in thirties- were likely to display a more authoritarian parenting style than females, while females from both generations were likely to display more authoritative parenting styles than males. However males from rather generation did not have a more permissive style of parenting than females. A generational change in parenting styles toward a more lenient and democratic style may have occurred- in smaller generationwhich may reflect an overall societal trend towards an authoritative child rearing style (Zervides et al., 2007). Not only parents' gender affects parenting styles, but children's gender affects them also; as researches on Arabic societies indicate that: authoritarian style was higher among males, whereas the mean score of the authoritative style was higher among females (Dwairy, 2006). Mothers verses Fathers: Researches have indicated that, mothers are more likely to manage their children's behaviors and activities and focus on providing basic needs (Parke 1995), While, fathers' time with children is less frequent but can be characterized by more play (Pleck \& Masciadrelli, 2004; Parke \& Buriel, 2006; Yeung, Sandberg, David-Kean, \& Hofferth, 2001). Other studies show that, Fathers may help 
their children to develop self-identity (Shulman \& Klein, 1993 all in Tahseen, 2005). Another deferential variable among fathers and mothers is the increase of educated and working mothers in many societies throughout the world, mother has gained economic power as have working children, while the father has been losing his absolute control of the family. In Mongolia, for example, studies have found that children in urban areas side relay basically on their mothers; because she not only works and brings money in, but also cooks, cares for the house and for them (Georgas, 2003).

5) Socioemotional development and parental role as perceived: Studies comparing mainland China and other Chinese communities are rare, but are important to gaining a better knowledge of variation across Geographical locations. Berndt, Cheung, Lau, Hau, and Lew (1993) compared perceptions of parenting in three Chinese societies, mainland China, Taiwan, and Hong Kong. They reported that, not surprisingly, mothers were generally perceived as warmer as and less controlling than fathers. Daughters perceived their fathers as warmer and as less controlling than did sons. Also, Hong Kong adults perceived both parents as less warm and more controlling than adults from the other two communities. This result is consistent with more recent study of Lai, Zhang, and Wang (2000), who reported that mothers in Beijing, in comparison with mothers in Hong Kong, were less controlling and less authoritarian in disciplinary style, but were more inclined to show affection and to emphasize their children's achievement (Fho, 2001).

6) Only children: only children appear to enjoy advantages in environmental and health conditions, and tend to have broader interests, better cognitive development, and higher intellectual ability than children with siblings (Rosenberg \& Jing, 1996). However, results in the areas of personality and social functioning have been rather inconsistent. Chen, Rubin, and $\mathrm{Li}$ (1994) reported no significant differences between urban only and nononly children in social behavior, peer relationships, school-related social competence, and academic achievement (Fho, 2001).

7) Age: researches show that there is a distinction between adolescent perceptions of parent socialization practices and parents' beliefs about parenting practices, according to age variable. Parenting style is conceptualized as a variable that moderates the relation between parenting practices and developmental outcomes (Darling \& Steinberg, 1993 all in Tahseen, 2005).

8) Acculturation: can be defined as the process of adapting to a new culture through a course of changes in cultural attitudes, values, and behaviors following contact with two distinct cultures (e.g., Barlow, Taylor, \& Lambert, 2000; Feurtes \& Westbrook, 1996; Park \& Harrison, 1995; Rayle \& Myers, 2004). Immigrants face the dilemma of maintaining traditional values and adopting new ones. The reaction to a new host culture significantly affects child rearing practices (McGillicuddy-De Lisi \& Subramanian, 1996). When parents choose not to modify traditional values, for example, Asian American parents expect the child to be obedient yet paradoxically recognize that she/he must be independent in order to succeed in Western culture (Rhee, et al., 2003 all in Tahseen, 2005). Acculturation in this study presented in mixed culture, which appears here in immigrants, some Arabic countries and some occupied people, who adopted collective culture, then, exposed to individual one and absorbed some of its values, which conduct a new unique type.

\section{The Present Study}

From what previously stated, the current research aims and focuses on examining the most frequent variables that affect parenting styles (socialization), especially across cultures then comparing them with some variables within the same culture. From what stated in theoretical framework, first. Then second, compare it with what is actually happing at the author's country. Egyptian society has been chosen; as an example of a mixed culture society. From ancient, Egyptian society has exposed to different civilizations as well as cultures like Pharos, Greek, Roman, Coptic, Islamic, European and so on. So it becomes a good example of this mixed or melting pot type of culture. So it was hypothesized that:

1) There are co-variant variables that affect Parenting styles and can be classified within the same cultures and across cultures.

2) Acculturation may have the major impact on changing parenting styles, more than before.

\section{Method}

The method implies:

1) Psychoanalysis of the content. From the related studies and the theoretical framework, this is focusing on: analyze the family as a social system in different countries. Through classifying variables according to cultures and parenting styles. This is to answer these main questions:

-What are the indicator variables that reflect changes in parenting styles across cultures?-What is the main source of these changes? Are these from the same culture, or because of acculturation, or globalization?

2) Then examine this theoretical framework with a small pilot study.

\section{Procedures}

The researcher handled the idea through classifying variables as mentioned bellow:

1) Classified countries' cultures as shown in studies like this, type (A: Collective) culture founded mainly in: China, Russia. While type (B: Individual) culture founded mainly in: England, Bulgaria, European, White, Non-Muslim-American, Australia, Anglo- Australia, and Canada. Type (C: mixed culture founded mainly in: Asian, Colored, Muslim- American, Greek- Australian and Arabic countries in the sample with different levels.

2) Classified intermediate variables as shown in studies: AAge: pre-school, middle to late childhood and adolescence. BGender: male and female. C-Type of interaction inside the family: Positive, negative and mixed, which means that it was negative then, became mixture according to exposing to another culture, which have changed the type into dual interaction. Type of interaction means the impact of parenting styles within the family, type of relationship among family's members according to study's descriptions or results. Intermediate variables that mentioned before, all together shape this type of interaction or relationship. 
3) Classified parenting styles, according to studies, into four categories: Authoritarian, Authoritative, permissive and mixed. Mixed means that parenting style was authoritarian then became mixture; as it has appeared in samples from two generations, also in immigrants, occupied people and Arabic countries, because of acculturation. Description of Sample's variablesaccording to analyzing the theoretical frame work-is shown in tables, at the end of this research (Appendix A).

4) Examine (compare) the acculturation result by conducting small survey. Description of this small survey and its validity is shown at the end of this research (Appendix B).

\section{Analysis and Discussion}

1) Psychoanalysis of the content: Parenting style is best understood as a context within socialization occurs, it is important to analyze a family as a social system in different cultures. As Darling \& Sternberg suggested in 1993 "it is important to conduct further researches to answer the question: how does the influence of parenting styles vary as a function of the cultural background on developing person?”

According to this, the researcher here classified variables as below:

A) Variables within the same culture: as shown previous: first born child, parent economical and educational level, goodness of fit between parents and children, gender, mother versus father and generational changes in parenting, only child, and age.

B) Variables among cultures: appears in acculturation, as shown previous with the type of cultures: The analysis has been done from the previous theoretical framework and from previous related studies-a random sample-that has been done across cultures, which are from: (England, United States, Bulgaria, China, Russia, Taiwan, Australia, Canada, Yemen, Palestinian, Saudi, Egypt, Algeria, Jordan, and Lebanon); studies according to researchers and dates are: Moore, 1986. Greenberger, 1989; Watson, 1992; Darling et al., 1993; Fablo et al., 1993; Pratt, 1993; Bernita et al., 1995; Turner et al., 1995; Hart, 1998; Chen, 2000; Miller, 2001; Zhou, 2004; Tahseen, 2005; Ang, 2006; Costigan, 2006; Dwairy, 2006; Marie et al., 2007; Zervides et al, 2007; Cheah, 2009; Park, 2010. The tables presented variables according to studies are at the end of research.

C) Indications for similarities across cultures are:

a) The extension of nuclear family: parson theorized that the adaptation of the American family from its extended family system in agricultural areas to urban areas required a nuclear family structure. The young couple in the large city lived far away and was fragmented from their families in the small towns. The nuclear family became primarily a unit of residence and consumption. The financial and educative functions become dependent on the state, in contrast with the extended family in small towns. Thus, the nuclear family was isolated geographically and psychologically from its kin and its major remaining function was to provide for the psychological aspects of the family, such as the socialization of the children. Parsons argued that this social mobility which characterizes America was made possible by the breaking of family ties, but at the cost of psychological isolation. Actually, America had a long history, going back to colonial times, of the independent nuclear family, as did England, northern France and some other European countries (Georgas, 2003). Although studies of social networks in North America and Northern Europe in the past 40 years have indicated that the nuclear family is not isolated from its kin and independent to the degree assumed by Parsons and other sociologists of the family, Arabic studies in Egypt, Jordan and Suede Arabia in the past 40 years have shown that nuclear family becomes the basic type of the family through many of Arabic countries, especially in urban and industrial areas, as shown in several Arabic studies through the last 40 years.

b) Roles inside the same family: as reflection of economic changes- television, movies, education, the internet, tourism and commerce, so the traditional family systems of small societies are no longer totally dependent on subsistence systems such as hunting, gathering or even agriculture. The father no longer has absolute power in the family. According to this, mothers as working member has a significant role, so that the perception of gender has been changed in differentiation of male and female.

c) Pattern of parental socialization: Kagitcibasi has developed a model of family change based on socio-economic development in which she theorizes three patterns of family interaction: i) the traditional family in developing countries characterized by total interdependence between generations in material and emotional realms; ii) the individualistic nuclear family model of Western society based on independence, and iii) a synthesis of these two, involving material independence but psychological interdependence between generations (Georgas, 2003). This is also, true across cultures, developing and advanced one, as shown in several Arabic studies through the last 40 years.

If we analyze these results we may notice that the type of interaction inside the family is affected directly and indirectly by cultures; so culture have the major impact on parenting styles (Socialization) than other intermediate variables: such as gender or age; as culture may affect them indirectly in perception and behaviors among ages and genders. We also have noticed that the interaction among cultures, specially mixed one, has a significant impact on parenting styles. Also, we have noticed that the interaction with collective and mixed cultures has more impact on dependent variable. As a result of this, we may conclude that the collective cultures absorbed individual culture's value more than the individual one did, and become mixed culture. For example, one of the interesting results on Arab societies is that Egyptian, Algerians, and Palestinians in Israel scored high in both authoritarian and permissive styles. The mixed inconsistent pattern was at the highest level in Yemen and among the Palestinian citizens in Israel. This mixed pattern among the Palestinians in Israel may indicate the dual culture in which they live. On one hand, as Palestinians they share the Arabic authoritarian and collective culture, and on the other hand, as Israeli citizens they are exposed to Israeli-Western cultural influences. This dual culture may be expressed in this mixed and contradicting parenting style. The results obtained from the two samples of Palestinians indicate that the Palestinian Israeli citizens respond to exposure to the Israeli culture differently than the Palestinians under the Israeli occupation do. As citizens, they tend to absorb some liberal values, whereas under occupation they resist the Western influences. The inconsistent Pattern in Yemen may indicate new, rapid, Western influences that started only in the past decade during which the country moved from being a tribal society to being a democratic state. This abrupt transition to democracy occurred within 
less than a decade in a rural, nonindustrial society (Zakareya, 1999). Consequently, the tribal system was not dismantled. This fast transition, which was accompanied, of course, by many other cultural, educational, and economic changes, created a strange coexistence between the two systems (Dwairy, 2006). Goode's (China, 1963) thesis is that Western ideological influences, particularly the value of individual freedom of choice, may have their most powerful effect in other cultures through the changes they encourage within families. For example, in societies which have the practice of arranging marriages by parental choice, the appeal of Western practice of individual mate selection may undermine the traditional parent-child relationship. Changes within family micro system, toward greater individual choice and more democratic decision-making, eventually may affect changes at the social, macro system level (Quoss, 1995). There is no single or definitive model of parenting. What may be right for one family or one child may not be suitable for another. With authoritarian and permissive parenting-on opposite sides of the spectrum-most conventional and modern models of parenting fall somewhere in between (Maccoby, 1983; Chan et al., 2008).

2) The applied (pilot) study, according to these results: the author have done a limited survey on seven Egyptian families with thirty participants: parents in forties and children from preschool 6 old till 17 old-to examine the way (means their style or socialization) they rearing their children from their early childhood till teenage-and have found that:

- All families believe that Western culture affects Arabic one, now, and not vice versa. (Means the affection of western one is more than the Arabic one, now days, as they believe).

- The positive effects (from western culture) on Egyptian families or parenting styles- as they perceived are: becoming more permissive, give more freedom, interested in persistence, hard work and precision more than before.

- While, the negative effects on families, as they believe are: become more consumption, violent, not prosaically as before; because of involving in individual technological activities than before and finally, family neither the first frame of reference group for children, nor the most important one for them; as a first and a primary frame of reference group. Peer and internet social sites have more important role in socialization, nowadays than before, in our global era.

\section{Conclusion and Further View}

So that, culture can no longer be treated as a static variable in research, as if it was frozen in time. Another point is that we cannot consider the role of culture in isolation. Both official ideology and policies constitute an onslaught on cultural tradition. Ideology directs parents to bring up children with a socialist worldview, which in large measure clashes with traditional values. The open-door policy leads to an acceleration of cultural change (Fho, 2001). Cross-cultural research on parents' socialization goals and practices with young children has increasingly shown that parents promote aspects of both independence and interdependence in their children; as these studies have examined parent's long-term goals for their children's futures, which may be equally or more influential than short-term socialization goals on children's development (Cheng et al., 2007). So, a science of culture and parenting furnishes check against ethnocentric world views of parenting (Miller, 2001).

At last, the world is changing; the rapid development in communications from the past quarter century till now will cut all barriers among societies and merge different aspects of cultures into one new and strength culture that could stand and adjust with our new era requirements, that may select and merge different parenting styles to adjust the new era changing. And this is the new idea in the study, the importance of it, also. Mixed culture does not mean something positive or negative; otherwise, it is a description of new born culture; as a melting plot-melting pot here is a metaphor referring to the different elements "melting together" into a harmonious whole with a common culture, and as multiculturalists claim that assimilation can hurt minority cultures by stripping away their distinctive features. They point to situations where institutions of the dominant culture initiate programs to assimilate or integrate minority cultures (Millet, 2008). Here in this study- not minority but, national culture instead. The combination of all cultures that communicate and interact internationally together-not between two cultures or just few ones, but all over the world as a result of moving toward global culture, as well as an unique one. As Giger \& Davidhizer suggested: there are 6 categories that make a culture unique, the way their people communicate together, the space and time they live in, there social organization, environmental control and their biological variation (Giger \& Davidhizer, 1995). But the suggested unique here is in melting all barriers among cultures in this unique time, as moving toward one world with one global culture. According to these findings, results and suggested view, more researches are needed to examine this new type of mixed or global culture.

\section{References}

Ang, R. P. (2006). Effects of parenting style on personal and social variables for Asian Adolescents. American Journal of Orthopsychiatry, 76, 503-511. doi:10.1037/0002-9432.76.4.503

Bornstein, M. H., \& Bornstein, L. (2007). Parenting Styles and Child Social Development. Encyclopedia of Early Childhood Development. Center of Excellence for Early Childhood Development. URL (last checked 23 June 2111)

http://www.child-encyclopedia.com/en-ca/home.html

Chan, T. W., \& Koo, A. (2008). Parenting style and youth outcome in the UK. Oxford: University of Oxford.

Cheah, C. S. L., Leung, C. Y. Y., Tahseen, M., \& Schult, D. (2009). Authoritative parenting among immigrant Chinese mothers of preschoolers. Journal of Family Psychology, 23, 311-320. doi:10.1037/a0015076

Chen, X. L., \& Mowei, L. D. (2000). Parenting warmth, control, and indulgence and their relations to adjustment in Chinese: A Longitudinal study. Journal of Family Psychology, 14, 401-419. doi:10.1037/0893-3200.14.3.401

Cheng, C. C., \& Suizzo, M. A. (2007). Taiwanese and American mothers`goals and values for their children's futures. International Journal of Psychology, 42, 307-316.

Costigan, C. L., Bardina, P., Cauce, A. M., Kim, G. K., \& Latendresse, S. J. (2006). Inter- and Intra- variability in perceptions of behavior among Asian Americans and European. Cultural Diversity and Ethnic Minority Psychology, 12, 710-724. doi:10.1037/1099-9809.12.4.710

Darling, N., \& Steinberg, L. (1993). Parenting styles as context: An integrative model. Psychological Bulletin, 113, 487- 496. doi:10.1037/0033-2909.113.3.487

Dwairy, M., Achoui, M., Abouserie, R., Farah, A., Fayad, M. \& Khan, H. K. (2006) Parenting styles in Arab societies a first cross culture 
study. Journal of Cross Cultural Psychology, 37, 1-18. doi:10.1177/0022022106286922

Fho, D. F. (2001). Parenting in mainland China: Culture, ideology, and policy. The International Society of the Study of Behavioral Development Newsletter, 38, 7-8.

Gaber, A. E. H. \& El Khodarie, S. (1978). Psychological studies in Arabic personality. Cairo: Books World.

Georgas, J., \& Greece, A. (2003). Family: Variations and changes across cultures. URL (last checked 23 June 2011) http://www.wwu.edu/culture/georgea.htm

Giger, J. N., \& Davidhizar, R. E. (1995). Nature Recreation and Culture Diversity. URL (last checked 23 June 2011) http://www.uidaho.edu/cnr

Greenberger, E., \& Goldberg, W. A. (1989). Work, parenting, and socialization of children. Developmental psychology, 25, 22-35. doi:10.1037/0012-1649.25.1.22

Hart, C. H., Nelson, D. A., Robinson, C., Olsen, S. F., \& McNeilly, C. M. K. (1998). Overt and relational aggression in Russian nurseryschool- age children: Parenting style and marital linkage. Developmental psychology, 34, 687-697. doi:10.1037/0012-1649.34.4.687

John, A. (1968). Socialization and Society. URL (last checked 21 June 2011) http://www.answers.com/topic/socialization

Maccoby, E. E., \& Martin, J. A. (1983). Socialization in the context of the family: Parent-child interaction. In P. Mussen, \& E. M. Hetherington (Eds.), Handbook of child psychology, volume IV: Socialization, personality, and social development (pp. 1-101). New York, NY: Wiley.

Miller, J. G., \& Chen, X. (2001). Culture and Parenting. An overview. The International Society of the Study of Behavioral Development Newsletter, 38, 1-3.

Millet, J. (2008). Understanding American Culture: From Melting Pot to Salad Bowl. URL (last checked 15 July 2008) http://en.wikipedia.org/wiki/Melting_pot

Moore, E. G. (1986). Family socialization and IQ test performance of traditionally and transracially adopted Black children. Developmental Psychology, 22, 317-326. doi:10.1037/0012-1649.22.3.317

NYU Child Study Center (2010). Parenting Styles. Children's Treatments: The Match. URL www.aboutourkids.org

Ontai, L. L., \& Mastergeorge, A. M. (2010). Culture and parenting, a guide for delivering parenting curriculums to diverse families. Families with Young Children Workgroup. URL (last checked 23 June 2011) http://ucce.ucdavis.edu/files/filelibrary/5264/20355.pdf

Park, Y. S., Kim, B. S. K., Chiang, J. J., \& Charlene, M. (2010). Ac- culturation, enculturation, parental adherence to Asian cultural values, parenting styles, and family conflict among Asian American college students. Asian American Journal of Psychology, 1, 67-79. doi:10.1037/a0018961

Pratt, M. W., Hansberger, B., Pancer, S. M., Roth, D., \& Santolupo, S. (1993). Thinking about parenting: Reasoning about development issues across the life span. Developmental Psychology, 29, 585-595. doi:10.1037/0012-1649.29.3.585

Quoss, B., \& Zhao, W. (1995). Parenting Styles and Children's with Parenting in China and the United States. URL (last checked 23 June 2011) http://www.questia.com/googleScholar

Reber, A. (1995). Dictionary of psychology. England: Penguin Group.

Rohner, R. P., \& Khaleque, A. (2002). Parental acceptance-rejection and life-span development: A universal perspective. In W. J. Lonner, D. L. Dinnel, S. A. Hayes, \& D. N. Sattler (Eds.), Online readings in psychology and culture (Unit 11, Chapter 4). Washington: (http://www.wwu.edu/ culture), Center for Cross-Cultural Research Western Washington University.

Tahseen, M., Rubin, K. H., \& Dwyer, K. M. (2005). The Influence of Culture: Parenting Differences among Muslim-American and Non Muslim-American Mothers and Fathers. Online Power Point Presentation.

Tcet (2010). Parent Teacher Education Connection. Parenting Styles. URL (last checked August 2010) http://www.tcet.unt.edu/

Turner, P. J., \& Gervai, J. (1995). A Multidimensional study of gender typing in preschool children and their parents: Personality, attitudes, preferences, behavior, and cultural differences. Developmental Psychology, 31, 759-772.doi:10.1037/0012-1649.31.5.759

Watson, P. J., Little, T., \& Biderman, M. D. (1992). Narcissism and parenting styles. Psychoanalytic Psychology, 9, 231-244. doi: $10.1037 / \mathrm{h} 0079344$

Wong, K. (2002). The differences in Parenting Styles and Family Structure of Two Different Cultures. URL (last checked 22 November 2008)

http://www.mightystudents.com/essay/Differences.Parenting.Styles. 76695

Zervides, S., \& Knowles, A. (2007). Generational changes in parenting styles and the effect of culture. E-Journal of Applied Psychology, 3, 65-75.

Zhou, Q., Eisenberg, N., Wang, Y., \& Reiser, M. (2004). Chinese children's effortful control and dispositional anger/ frustration: Relations to parenting styles and children's social functioning. Developmental Psychology, 40, 352-366. doi:10.1037/0012-1649.40.3.352 


\section{Appendix}

\section{Appendix A}

The following are: tables describe the random sample of studies. As shown in previous theoretical framework.

Tables as appeared in the following page from Table 1 to 6 .

Table 1.

Sample description according to its societies.

\begin{tabular}{lll}
\hline Societies & Numbers & Ratio \\
\hline England & 151 & $2.1 \%$ \\
Bulgaria & 151 & $2.1 \%$ \\
Asian-American & 323 & $4.49 \%$ \\
China & 1825 & $25.38 \%$ \\
Asia & 548 & $7.65 \%$ \\
European-American & 211 & $2.96 \%$ \\
White-American & 174 & $2.4 \%$ \\
Russia & 207 & $2.88 \%$ \\
Colored-American & 46 & $0.64 \%$ \\
Non Muslim-American & 64 & $0.89 \%$ \\
Muslim-American & 64 & $0.89 \%$ \\
Twain & 201 & $2.79 \%$ \\
Australia & 100 & $1.39 \%$ \\
Greek-Australia & 65 & $0.9 \%$ \\
Anglo-Australia & 65 & $0.9 \%$ \\
Canada & 100 & $1.39 \%$ \\
Arab Countries: Yemen, Palestin- & & \\
ian-Israel, Palestine, Saudi, Egypt, & & \\
Algeria, Jordan, Lebanon. & 2893 & $100 \%$ \\
Total & 7188 & \\
\hline
\end{tabular}

Table 2.

Sample description according to age.

\begin{tabular}{lll}
\hline Age & Numbers & Ratio \\
\hline Pre-School: 2 - 6 years & 1100 & $15.3 \%$ \\
Middle to late childhood: 7 - 12 years & 2048 & $28.49 \%$ \\
Adolescence: 13 - 19 year & 4040 & $56.21 \%$ \\
\hline
\end{tabular}

Table 3.

$\equiv$ le description according to cultures.

\begin{tabular}{lll}
$\sqrt{\text { Cultures }}$ & Number of cases & Ratio \\
Cultures & 2658 & $36.98 \%$ \\
\hline Collective & 1600 & $22.26 \%$ \\
Individual & 2930 & $40.76 \%$ \\
Dual(mixed) & & \\
\hline
\end{tabular}

Table 4.

Sample description according to parenting styles.

\begin{tabular}{lll}
\hline Parenting styles & Number of cases & Ratio \\
\hline Authoritarian & 1900 & $26.43 \%$ \\
Authoritative & 2308 & $32.12 \%$ \\
Permissive & 400 & $5.56 \%$ \\
Mixed & 2580 & $35.89 \%$ \\
\hline
\end{tabular}

Table 5.

Sample description according to type of interaction inside the family.

\begin{tabular}{lll}
\hline Type of interaction & Number of cases & Ratio \\
\hline Positive & 2905 & $40.41 \%$ \\
Negative & 1283 & $17.85 \%$ \\
Mixed & 3000 & $41.74 \%$ \\
\hline
\end{tabular}

Table 6.

Sample description according to Gender.

\begin{tabular}{lll}
\hline Gender & Number of cases & Ratio \\
\hline Female (Mothers, daughters) & 3688 & $51.31 \%$ \\
Male (Fathers, sons) & 3500 & $48.96 \%$ \\
\hline
\end{tabular}

\section{Appendix B: The Small Applied (Pilot) Study}

Table 7.

Questionnaire description.

\begin{tabular}{lll}
\hline Items & Responses & Ratio \\
\hline $\begin{array}{l}\text { 1) Western cultures have } \\
\text { more impact on Arabic }\end{array}$ & Yes. & $100 \%$ \\
ones. & No. & $0 \%$ \\
2) The positive effects & - Becoming more permissive. & $30.3 \%$ \\
(from western culture) on & - Give more freedom, interested & $30.3 \%$ \\
Egyptian families or & in persistence. & \\
parenting styles are: & - Hard work and precision more & $30.3 \%$ \\
& than before. & \\
& & $20 \%$ \\
& - Become more consumption & $15 \%$ \\
3) The negative effects on & than before. & $5 \%$ \\
families are: & - Violent. & $60 \%$ \\
& - Family neither the first frame & \\
& of reference group for their \\
& children, nor the most important & \\
& one for them. & \\
\hline
\end{tabular}

Scale validity has been compared with the theoretical frame work as external criteria, while scale reliability by Alfa was 0.71 . 